MARTINS et all , v(11), no 11, p. 2357-2365, JUN, 2013.

Rev. Elet. em Gestão, Educação e Tecnologia Ambiental (e-ISSN: 2236-1170)

\title{
GESTÃO DA ATIVIDADE RURAL: UM ESTUDO JUNTO AOS COMPRADORES DE MÁQUINAS AGRÍCOLAS VISITANTES DA EXPOINTER - ESTEIO/RS
}

\section{MANAGEMENT OF RURAL ACTIVITY: A STUDY AMONG BUYERS OF AGRICULTURAL MACHINERY VISITORS EXPOINTER - ESTEIO/RS}

\author{
Katia Celene Martins ${ }^{1}$, Jaqueline Carla Guse ${ }^{2}$, Andrea Cristina Dorr ${ }^{3}$, Marivane Vestena Rossato ${ }^{4}$, \\ Luiz Antônio Rossi de Freitas ${ }^{5}$ \\ ${ }^{1}$ Universidade Federal de Santa Maria (UFSM) - Bacharel em Ciências Econômicas. E-mail: katiamartins@gmail.com; \\ ${ }^{2}$ UFSM - Aluna do curso de Ciências Contábeis. E-mail: drjaquelinecarla@yahoo.com.br; \\ ${ }^{3}$ UFSM - Profa. Adjunto do Departamento de Ciências Econômicas. E-mail: andreadoerr@yahoo.com.br; \\ ${ }^{4}$ UFSM - Profa. Adjunto do Departamento de Ciências Contábeis. E-mail: marivavest@gmail.com; \\ ${ }^{5}$ UFSM - Prof. Adjunto do Departamento de Ciências Contábeis. E-mail: luizrf@terra.com.br.
}

http://dx.doi.org/10.5902/223611708776

\begin{abstract}
RESUMO
Devido à grande importância social e econômica do agronegócio, este estudo busca identificar os fatores determinantes que mais influenciam na decisão de compra de máquinas agrícolas. Para alcançar o objetivo foi realizada uma análise do processo de tomada de decisão afetuada pelos produtores rurais, identificando o perfil destes produtores e quais os fatores mais valorizados no momento da compra. Inicialmente, realizou-se uma abordagem sobre a indústria de máquinas e implementos agrícolas no Brasil e no Rio Grande do Sul e suas estatísticas de produção e vendas. Após, fez-se uma revisão bibliográfica sobre o processo de tomada de decisão. A metodologia utilizada neste trabalho é um estudo exploratório através de pesquisa de campo realizada no ano de 2011 na exposição internacional de Animais, Máquinas, Implementos e produtos Agropecuários (EXPOINTER) - Esteio/RS, através da aplicação de um questionário semi-estruturado. Conclui-se que os principais fatores que determinam a compra estão relacionados com a facilidade operacional, confiança na marca, opinião de amigos e especialistas e a forma de financiamento.
\end{abstract}

Palavras-chave: agronegócio, decisão de compra, máquinas agrícolas

\begin{abstract}
Considering the great social and economic importance of the agribusiness, this research seeks to identify the determinant factors that influence the most the decision taking of rural producers on agricultural machineries. In order to achieve this objective, an analysis of the decision making procedure was done by rural producers, identifying their profile and which factors are the most relevant in the moment of purchasing. Initially, we did an overview of the industry and agricultural implements in Brazil and in the Rio Grande do Sul state and show its statistics of production and sales. The methodology used is this research is based on an exploratory study through field research conducted on August, 28, 2011 at the International Exposition of Animals, Machineries, Implements and Rural Products (EXPOINTER) - Esteio-RS through the application of a semi-structured questionnaire. It is concluded that the main factors that determine the choice are related with the operational procedure, trust on label, friends and experts' opinion and the financing form.
\end{abstract}

Keywords: agribusiness, agricultural machineries, decicion making 


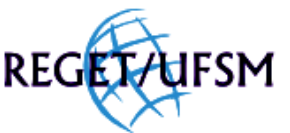

MARTINS et all , v(11), no 11, p. 2357-2365, JUN, 2013.

Rev. Elet. em Gestão, Educação e Tecnologia Ambiental (e-ISSN: 2236-1170)

\section{INTRODUÇÃO}

A tecnologia tem desempenhado um papel muito importante nos meios produtivos desde a revolução industrial. Seu uso não ocorre apenas na indústria, mas também no meio rural, onde o seu uso vem se intensificando nas últimas décadas. Segundo Guimarães (1982), a expansão industrial foi um fator propulsor da substituição dos métodos tradicionais na agricultura por um cenário onde a tecnologia aparece com papel de destaque. Citam-se vários motivos que levam ao uso de maquinário na agricultura, entre eles, a facilidade de manejo, a padronização dos serviços realizados, a facilidade de realizar serviços que demandariam grande porção de mão-de-obra, economias de escala, entre outros.

No Brasil, a partir da década de 1950, a agricultura passou por um período de modernização (SILVA, 1996). Segundo a Associação Brasileira da Indústria de Máquinas e Equipamentos (ABIMAQ), o segmento da indústria que produz máquinas e implementos agrícolas registrou em setembro de 2010 um faturamento nominal de $\mathrm{R} \$ 727,5$ milhões, valor que mostra expansão de $2,4 \%$ em relação a agosto do mesmo ano (R\$ 710,6 milhões). Sobre os $\mathrm{R} \$ 630,7$ milhões de setembro de 2009 , o faturamento do segmento cresceu $15,3 \%$ e no acumulado de janeiro a setembro, o faturamento nominal desse segmento da indústria foi de $R \$ 5,671$ bilhões, valor que supera em $35,2 \%$ os $R \$ 4,194$ bilhões dos primeiros nove meses de 2009.

Segundo Callado e Moraes Filho (2005), a identificação e a ponderação dos principais aspectos relacionados a determinado contexto têm importante papel no processo de tomada de decisão, agindo como referência coletora de dados relevantes sobre custos, despesas, mercado e tecnologias. Muitos agricultores tomam suas decisões baseadas em tradições, tornando a decisão no agronegócio muito complexa. A influência destes elementos na decisão depende também dos diferentes tipos de agricultores. Tais decisões tomadas e as ações implementadas, associadas às condições de produção, determinam diferentes níveis de acumulação e possibilidade de reprodução das propriedades. Independendo do tipo de agricultor, dentro da sua realidade ele busca satisfazer a sua necessidade diante das oportunidades que lhe são apresentadas, ele faz sua análise e toma decisões considerando a melhor combinação de fatores.

O mercado do agronegócio tem grande interesse em conhecer o seu público, pois de acordo com suas necessidades, são desenvolvidas e aperfeiçoadas as novas máquinas agrícolas. Para Frederico e Robic (2006), a satisfação do consumidor é fonte de feedback sobre a qualidade e atributos disponíveis que possam proporcionar decisões de marketing de uma organização, influenciando a formação da intenção de compra futura do consumidor. Destaca-se que as aquisições de novas tecnologias representam parcela considerável do capital empregado, sendo assim evidencia-se a importância da identificação dos fatores que influenciam na decisão sobre a compra dos maquinários.

Através da coleta de informações junto a vários consumidores é possível identificar os estímulos mais frequentes que suscitam interesse em uma categoria de produtos. É a partir do interesse em um produto ou serviço, que o comprador busca maiores informações. As fontes de informações podem ser pessoais (família, amigos, vizinhos, conhecidos), fontes comerciais (propaganda, vendedores, representantes, embalagens, mostruários), públicas (meios de comunicação de massa, organizações de classificação de consumo) e experimentais (manuseio, exame, uso do produto) (KOTLER, 2000).

Ao realizar uma intenção de compra, o consumidor pode passar por cinco subdecisões de compra: decisão por marca, decisão de fornecedor, decisão por quantidade, decisão por ocasião e decisão por forma de pagamento. Após comprar um produto, o consumidor experimenta algum nível de satisfação ou insatisfação (KOTLER, 2000). 


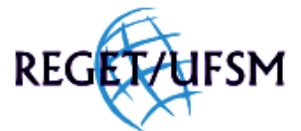

MARTINS et all , v(11), no 11, p. 2357-2365, JUN, 2013.

Rev. Elet. em Gestão, Educação e Tecnologia Ambiental (e-ISSN: 2236-1170)

O agronegócio brasileiro, em 2011, voltou sua atenção a 34 Exposição de animais, máquinas e produtos agropecuários (EXPOINTER) que ocorreu entre os dias 27 de agosto e 4 de setembro, no Parque Assis Brasil, em Esteio-RS, onde foram lançadas diversas máquinas que aliam inovação e qualidade. Diversos municípios estiveram presentes representados por suas concessionárias. Algumas novidades buscaram conquistar os pretensos compradores, com máquinas de grande potência, elevado rendimento, baixo nível de ruído, proporcionando maior conforto, outras permitem fácil acesso aos componentes que exigem verificações mais frequentes e simplificam sua manutenção.

Durante o evento, o produtor teve a chance de conhecer os equipamentos que melhor se enquadram as suas necessidades e ainda obter informações técnicas dos maquinários. Dessa forma, estas informações auxiliam no seu processo decisório da compra, onde ele pode esclarecer suas dúvidas, como também verificar as opções de financiamentos, visto que nestas feiras muitos atrativos e condições especiais são oferecidos.

Devido a grande importância da EXPOINTER no agronegócio, que é considerada uma das mais tradicionais feiras da América Latina, tornou-se possível contatar com representantes das mais renomadas concessionárias de máquinas agrícolas e produtores rurais. Portanto, este trabalho tem como problema de pesquisa: Quais são fatores determinantes que influenciam na compra de máquinas? Dessa forma, o objetivo geral deste trabalho consiste em analisar o processo de tomada de decisão adotado pelos produtores agropecuários no momento da compra de máquinas e equipamentos agrícolas. Objetiva-se ainda identificar o perfil dos compradores de máquinas e verificar quais são os fatores que influenciam a tomada de decisão frente à compra de máquinas agrícolas pelos produtores rurais.

O trabalho está estruturado em quatro seções. Após a introdução, ora apresentada, aborda-se a metodologia, onde são abordadas as técnicas de pesquisa utilizadas para realização do trabalho. Em seguida, apresenta-se a seção dos resultados, que tem por fim apresentar os resultados obtidos na pesquisa. E por último, as considerações acerca da gestão da atividade rural junto aos compradores de máquinas agrícolas visitantes da EXPOINTER - Esteio/RS.

\section{METODOLOGIA}

\section{Características da pesquisa de campo}

Dentre os procedimentos técnicos utilizados, este estudo se caracteriza como uma pesquisa de campo. Segundo Gil (2007), este tipo de pesquisa permite que o entrevistador tenha interação direta com o entrevistado de forma a explorar não somente as respostas fornecidas, como também de identificar respostas que não condizem com a realidade.

Gil (2007) diferencia os instrumentos de coleta de dados mais usuais como questionário, entrevista e formulário. Questionário trata-se de questões respondidas pelo próprio entrevistado, entrevista envolve o entrevistador e o entrevistado com aquele formulando perguntas a este (quando a entrevista for totalmente estruturada, isto é, com perguntas fixas, confunde-se com o formulário) e formulário é a técnica em que o pesquisado responde questões previamente elaboradas pelo pesquisador e este anota as respostas. Segundo Gil (2007), "por ser aplicável aos mais diversos segmentos da população e por possibilitar a obtenção de dados facilmente tabuláveis e quantificáveis, o formulário constitui hoje a técnica mais adequada nas pesquisas de opinião e de mercado". Desse modo, essa pesquisa utilizou-se de um formulário. 


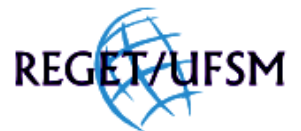

MARTINS et all , v(11), no 11, p. 2357-2365, JUN, 2013.

Rev. Elet. em Gestão, Educação e Tecnologia Ambiental (e-ISSN: 2236-1170)

\section{Fonte e análise dos dados}

A pesquisa de campo foi realizada em agosto de 2011 durante a 34 ${ }^{\circ}$ Exposição Internacional de Animais, Máquinas, Implementos e Produtos Agropecuários (EXPOINTER), a qual ocorre anualmente no Parque de Exposições Assis Brasil no município de Esteio - RS. A feira teve, em 2011, 456.365 visitantes e o setor de máquinas alcançou o valor de $\mathrm{R} \$ 834.700 .000,00$. Foram entrevistados 72 produtores rurais que utilizam máquinas agrícolas.

Os produtores rurais foram escolhidos de forma aleatória dentre os que estavam transitando no parque de máquinas. Foram aplicados formulários semiestruturados, visando explorar as características dos produtores frente à compra de máquinas e equipamentos. $\mathrm{O}$ formulário de máquinas agrícolas abordou, primeiramente, uma breve descrição do perfil da propriedade, o controle dos custos que o produtor realiza a descrição do maquinário próprio utilizado no manejo da terra e a possibilidade de arrendamento de máquinas de terceiros ou para terceiros.

Após essas perguntas passou-se a questões que buscam mensurar a relevância de cada fator na hora da compra da máquina ou equipamento que o produtor julga ser o mais importante para a sua atividade. Os fatores analisados foram: facilidade operacional, financiamento público/privado, confiança na revenda, recomendação técnica, propaganda, opinião de amigos/parentes, preço, marca e potência.

Os dados foram tabulados e analisados de forma qualitativa e quantitativa buscando-se caracterizar o perfil dos compradores e identificar as variáveis que influenciam a tomada de decisão de máquinas.

\section{RESULTADOS E DISCUSSÕES}

\section{Perfil Socioeconômico}

Os dados mostram que $91 \%$ da população compradora de máquinas agrícolas é masculina e $9 \%$ é feminina. Esse fato pode ser considerado frequente, uma vez que, esses dados podem ser corroborados com os dados encontrados por Silva et al. (2010), em seu estudo sobre as práticas de gestão utilizadas no gerenciamento das pequenas propriedades rurais de Guaramirim, em que $96,1 \%$ dos entrevistados eram do sexo masculino. No que se refere à idade dos compradores, os dados mostram que os entrevistados possuem, em média, 46,23 anos de idade. De acordo com a Figura 1, verifica-se que $13 \%$ possuem entre 18 e 30 anos, $22 \%$ de 31 a 40 anos, $31 \%$ entre 41 e 50 anos, e na categoria com idade igual ou acima de 51 anos, $34 \%$ do total. Portanto, o público mais jovem corresponde a menos da metade dos pesquisados, sendo a faixa etária igual ou acima de 51 anos a mais representativa, assim como a predominância masculina no setor de agronegócios. Esses dados mostram que o comprador de máquinas agrícolas está inserido em todas as faixas de idade, apontando para a atenção das empresas no tocante a produtos inovadores e que atendam aos anseios desse público. 


\section{REGEXAFSM}

MARTINS et all , v(11), no 11, p. 2357-2365, JUN, 2013.

Rev. Elet. em Gestão, Educação e Tecnologia Ambiental (e-ISSN: 2236-1170)

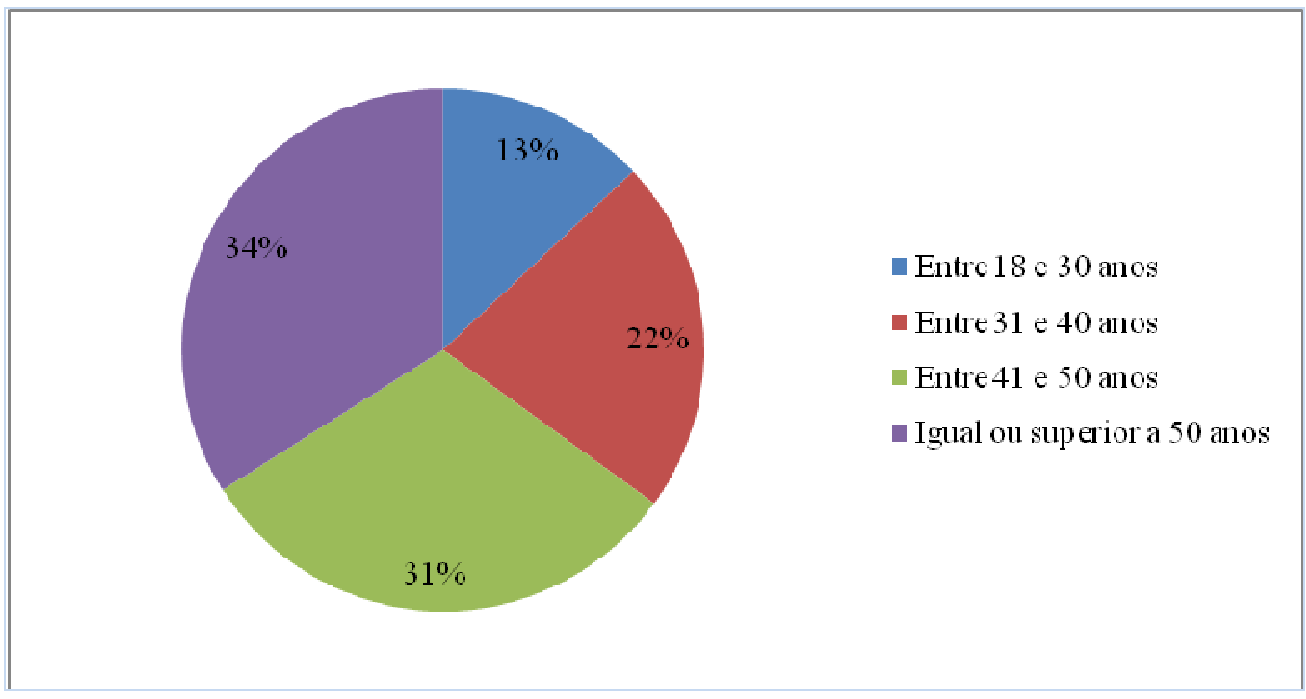

Figura 1. Perfil etário dos agricultores entrevistados na Expointer Esteio/RS

Fonte: Elaborado pela autora a partir de dados primários em pesquisa de campo.

A renda bruta anual informada pelos entrevistados é de $R \$ 365.536,60$. A análise de correlação é muito baixa $[0,0062]$ entre a idade e o nível de renda, ou seja, a idade não possui nenhuma correlação com o nível de renda auferido na propriedade.

Em relação à escolaridade, os dados revelam que, em média, os entrevistados possuem 9,35 anos de estudo, o que equivale ao ensino médio incompleto. A correlação entre idade e escolaridade resultou no índice de -0,1292. Apesar de o índice ser relativamente baixo, percebe-se uma relação inversa entre idade e anos de estudo. Isso significa dizer que produtores mais velhos possuem menos anos de estudo.

\section{Gestão da propriedade e controle de custos}

Na Figura 2 é observado que somente alguns produtores utilizam algum tipo de gestão contábil no gerenciamento das atividades com máquinas na propriedade. Os produtores puderam escolher uma das opções. Desta forma, 36,39\% afirmam que fazem a contabilidade, enquanto que 31,94\% apenas guardam os recibos e notas e $41,67 \%$ fazem o controle em cadernos ou planilhas. Observa-se que o restante dos entrevistados não utiliza nenhuma forma de registro ou controle. Esses dados revelam que os produtores compradores de máquinas agrícolas estão preocupados em ter algum tipo de controle da propriedade, uma vez que através do estudo de Silva et al. (2010), pode-se perceber que apenas $38,2 \%$ dos produtores entrevistados registram as informações em cadernetas e a maioria $(59,2 \%)$ não possui nenhum tipo de registro. Este resultado indica que muitos produtores não visualizam suas propriedades como empresas e tampouco se preocupam em contabilizar os gastos com o maquinário. 
Rev. Elet. em Gestão, Educação e Tecnologia Ambiental (e-ISSN: 2236-1170)

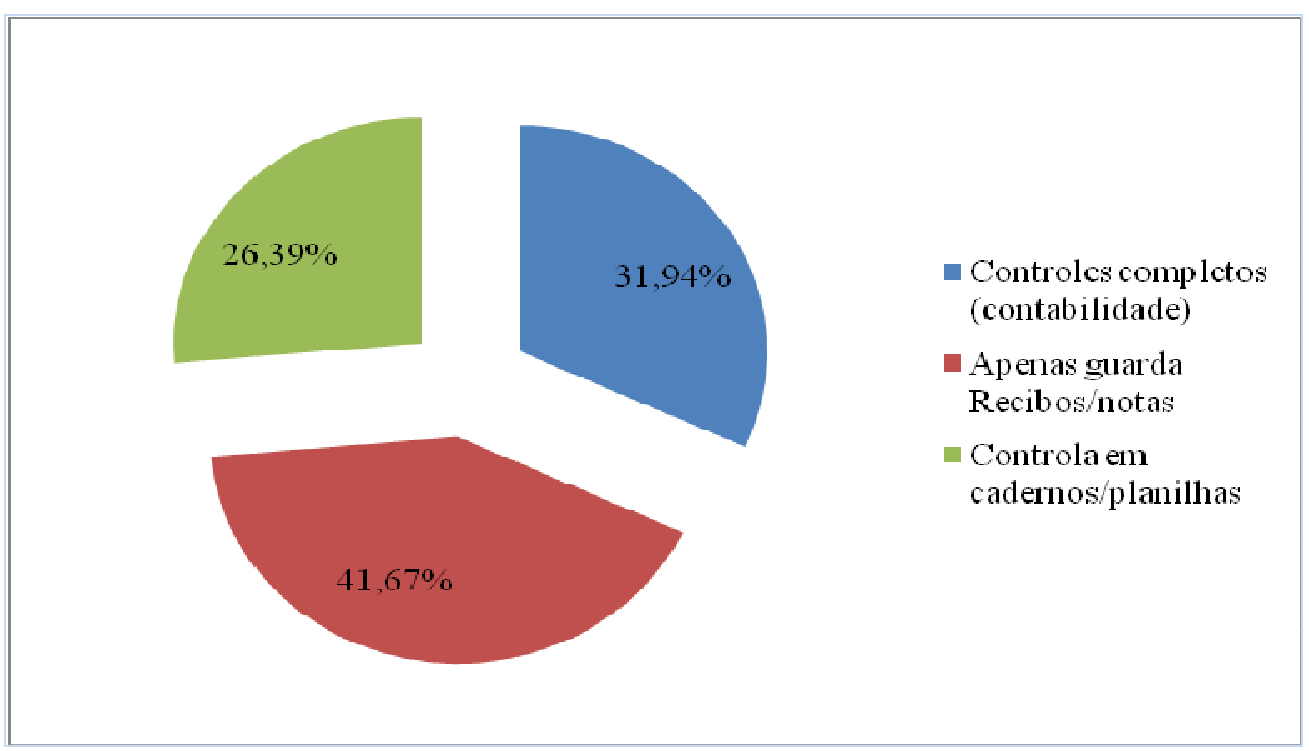

Figura 2. Tipo de instrumento de gestão contábil utiliza para gerir as atividades com maquinários Fonte: Elaborado pela autora a partir de dados primários em pesquisa de campo.

Conforme a Figura 3, 55,55\% dos entrevistados não separa os custos da propriedade com os custos da casa. Este resultado mostra que a falta de um sistema de gestão pode comprometer os resultados reais alcançados na produção agrícola e pecuária.

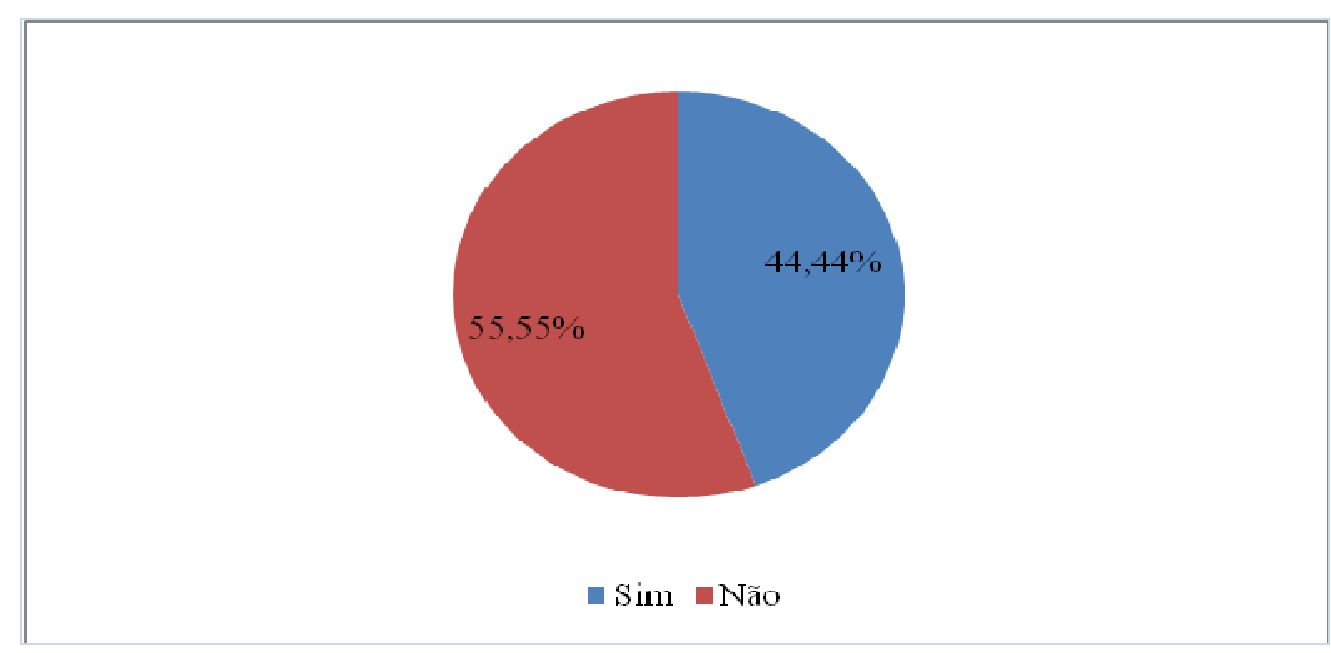

Figura 3. Separa os custos da propriedade dos custos da casa Fonte: Elaborado pela autora a partir de dados primários em pesquisa de campo.

Conforme discutido anteriormente, apesar da maioria dos entrevistados não terem um controle contábil no gerenciamento de maquinários, a Figura 4 mostra que $62,50 \%$ realizam o controle de estoque 


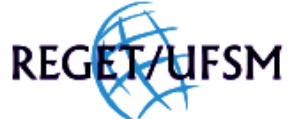

MARTINS et all , v(11), no 11, p. 2357-2365, JUN, 2013.

Rev. Elet. em Gestão, Educação e Tecnologia Ambiental (e-ISSN: 2236-1170)

de insumos no que se refere a maquinários. Outros $43,05 \%$ fazem o controle de estoque de produtos e, aproximadamente, $28 \%$ faz de combustível e somente $20 \%$ de peças.

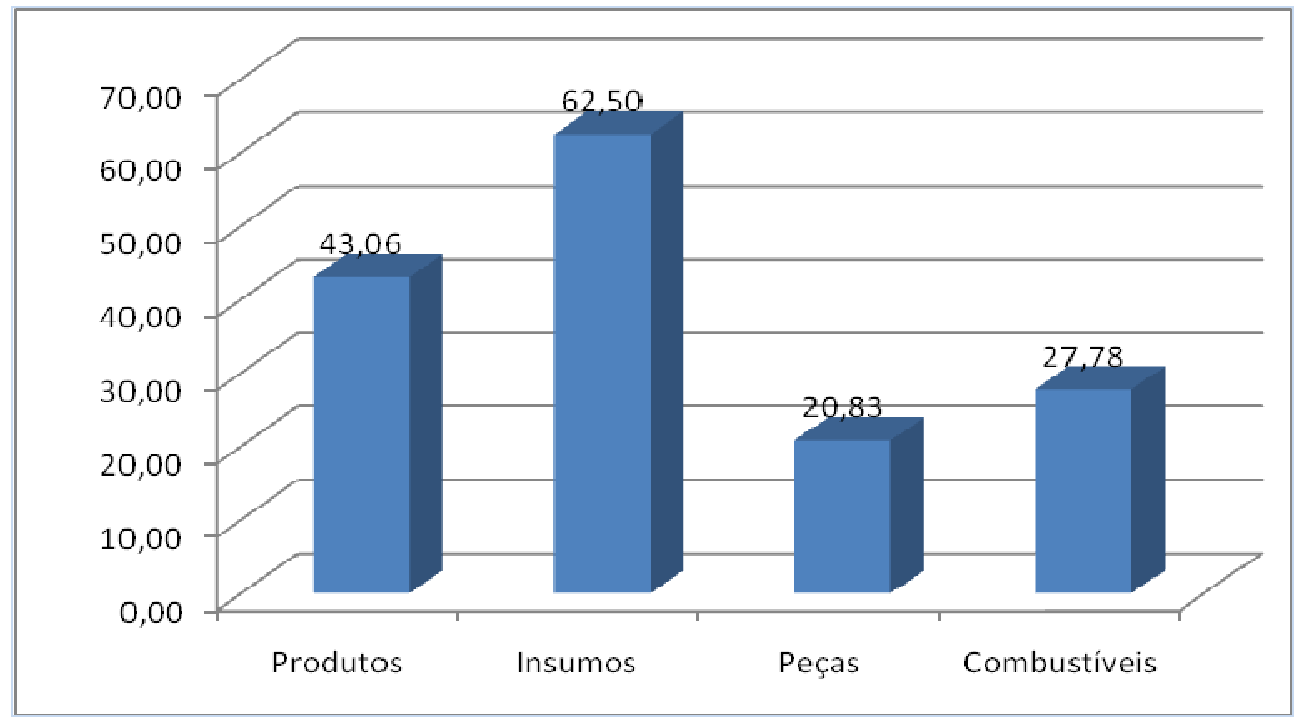

Figura 4. Realiza controle de estocagem

Fonte: Elaborado pelos autores a partir de dados primários em pesquisa de campo.

\section{Tomada de decisão na compra de máquinas}

A tomada de decisão na compra de máquinas envolve, desde princípios psicológicos, culturais e de tradição além de outros fatores como preço, marketing e opinião de terceiros. Os resultados da pesquisa mostram que a confiança na marca do maquinário é o atributo com maior peso na hora da compra para $83,33 \%$ dos entrevistados.

A facilidade operacional é o segundo pré-requisito mais importante na aquisição de máquinas agrícolas para $80,55 \%$. Com a facilidade operacional se economiza tempo no manejo da máquina e também na adaptação do operador de máquinas. Máquinas muito complexas dificultam o seu uso, pois a agilidade e o rendimento estão diretamente ligados à facilidade de manejo, sendo que uma dificuldade de operação comprometeria a eficiência do serviço e em consequência o rendimento do funcionário.

Quanto à recomendação técnica, 70,83\% dos agricultores responderam ser de muita importância, visto que se torna imprescindível o acesso às informações técnicas a respeito de determinado maquinário baseadas na experiência ou na opinião de pessoas próximas.

O valor de revenda foi citado por 55,55\% dos entrevistados. Este resultado confirma a importância que o preço do produto exerce sobre o consumidor, dada a sua restrição orçamentária. 0 preço destaca-se, pois ele mesmo afeta diretamente o seu orçamento, o que altera os rumos de todo o seu planejamento no longo prazo. 


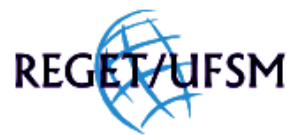

MARTINS et all , v(11), no 11, p. 2357-2365, JUN, 2013.

Rev. Elet. em Gestão, Educação e Tecnologia Ambiental (e-ISSN: 2236-1170)

A opinião de amigos e parentes também possui grande importância na tomada de decisão do consumidor de máquinas agrícolas, pois, foi apontado por $63,88 \%$ dos entrevistados. Neste ponto se percebe que o meio no qual o indivíduo está inserido exerce bastante influência sobre ele. Essa influência se consorcia com a racionalidade limitada do consumidor, pois ele não possui uma simetria completa de informações. O que o leva a ser influenciado por indivíduos que talvez possuam menos conhecimento sobre o assunto do que ele mesmo, mas por uma relação de amizade e confiança acabam influenciando as suas decisões de compra.

Quanto às formas de financiamento, revelou-se que o financiamento público, que obteve a opinião de $63,88 \%$ dos agricultores, ainda é a opção de maior importância em relação ao financiamento privado que atingiu $36,11 \%$ dos entrevistados. A opção pelo financiamento público ainda faz parte da realidade de muitos produtores, apesar do crédito privado estar consolidando seu espaço no mercado.

Altos investimentos e gastos vêm são realizados em publicidade e propaganda por todas as indústrias, inclusive nas destinadas ao meio agrícola ( $A B I M A Q, 2010)$. Embora a pesquisa revele que a propaganda não apresenta grande importância na decisão de compra, atingindo apenas 33,33\% dos entrevistados. Os produtores direcionam sua atenção para a necessidade real da compra do implemento e nas condições para efetivação da mesma, demonstrando que dificilmente um agricultor compraria um maquinário por catálogo ou anúncios de revistas. O design obteve o mesmo grau de importância que a propaganda, que da mesma forma obteve 24 indicações. Este resultado confirma que o consumidor de máquinas agrícolas está mais interessado no desempenho do bem do que em sua aparência e forma.

\section{CONCLUSÕES}

Constatou-se uma predominância de determinados atributos na tomada de decisão pela compra de máquinas durante a EXPOINTER edição 2011 realizada no município de Esteio-RS. Fatores como a confiança na marca, a facilidade operacional e o valor de revenda, opinião de amigos e parentes, recomendação técnica e formas de financiamento destacam-se na tomada de decisão. Por outro lado, fatores como propaganda e design não exercem muita influência.

Dessa forma, conclui-se que é necessário ressaltar as vantagens para as empresas fabricantes de maquinário agrícola dos fatores como facilidade operacional, marca do implemento e o valor de revenda. Salienta-se a importância das recomendações técnicas na compra de máquinas agrícolas, pois a decisão da compra sofre influência de sua e experiência de amigos e familiares como fatores determinantes para a compra de maquinário, utilizando também de informações vindas de pessoas especializadas.

Destaca-se a importância de recomendações técnicas, uma vez que elas buscam auxiliar o produtor na condução de seus negócios, de forma que sejam tomadas as melhores escolhas possíveis dentro de suas condições e necessidades. A forma de financiamento utilizada pelos produtores deve ser mais analisada. Estes financiamentos são de longo prazo, e podem comprometer uma parcela da renda por longo período. Por isso, devem-se analisar as possibilidades existentes no mercado e optar pela que melhor se adapta às condições do produtor.

O presente trabalho é limitado a um estudo exploratório aplicado somente a produtores rurais e não às revendas de máquinas. Cita-se ainda a brevidade do formulário aplicado, uma vez que as entrevistas 


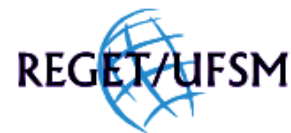

MARTINS et all , v(11), no 11, p. 2357-2365, JUN, 2013.

Rev. Elet. em Gestão, Educação e Tecnologia Ambiental (e-ISSN: 2236-1170)

foram feitas aleatoriamente nas mediações do evento. As pessoas geralmente estavam com pressa e não tinham muito tempo para respondê-lo.

Sugere-se que futuros trabalhos sejam focados de forma mais quantitativa na tomada de decisão de produtores rurais por máquinas agrícolas. Dessa forma, destaca-se a importância de utilizar outras ferramentas para delinear o perfil do produtor.

\section{REFERÊNCIAS BIBLIOGRÁFICAS}

ABIMAQ. Associação Brasileira da Indústria de Máquinas e Equipamentos. Disponível em: <http://www.abimaq.org.br>. Acesso em: 01 nov. 2010.

CALLADO, A. A. C.; MORAES FILHO, R. A. de. Gestão empresarial no agronegócio. In: CALLADO, Antônio André Cunha (Org.). Agronegócio. São Paulo: Atlas, 2005. p. 1-10.

FREDERICO, E.; ROBIC, A. R. Estudo dos fatores determinantes da satisfação do consumidor com vestuário infantil. [artigo científico]. 2006. Disponível em:

<http://www.anpad.org.br/evento.php?acao=trabalho\&cod_edicao_subsecao=149\&cod_eveno_edicao=10\&cod_edic ao_trabalho=5630>. Acesso em: 10 abr. 2011.

GIL, A. C. Métodos e técnicas de pesquisa social. 5a ed. São Paulo: Atlas, 2007.

GUIMARÃES, A. P. A crise agrária brasileira. Rio de Janeiro: Paz e Terra. 1979.

KOTLER, P. Marketing para o século XXI. São Paulo: Futura, 2000.

SILVA, J. G. A nova dinâmica da agricultura brasileira. 2 ed. rev. Campinas: UNICAMP, 1996.

SILVA, M. Z.; RECH, L. C.; RECH, G. M. Estudo sobre as práticas de gestão utilizadas no gerenciamento das pequenas propriedades rurais de Guaramirim. Ciências Sociais em Perspectiva, v. 17, n. 9, p. 57-74, 2010. 